\title{
Summary of: Influence of dental care on children's oral health and wellbeing
}

\section{FULL PAPER DETAILS}

1Sir John Walsh Research Institute, University of Otago, PO Box 647, Dunedin 9054, New Zealand ${ }^{*}$ Correspondence to: Bernadette K. Drummond Email: bernadette.drummond@otago.ac.nz

Refereed Paper

Accepted 4 April 2013

DOI: 10.1038/sj.bdj.2013.533

British Dental Journal 2013; 214: E27

\author{
B. K. Drummond, ${ }^{* 1}$ A. M. Meldrum ${ }^{1}$ and D. Boyd ${ }^{1}$
}

Background Dental problems in early childhood can have a very significant effect not only on the oral health of young children but on their quality of life and that of their families. Added to this are the long term risks they carry into the permanent dentition. Aim To review current literature on the management of early childhood caries and its influence on wider oral and general health. Results Recent studies suggest that the risks for dental caries, periodontal disease, malocclusion and other general health problems including overweight and obesity may be increased in children who have had early childhood caries. Traditional restoration of damaged primary teeth has been shown to have only moderate outcomes depending on the techniques and materials used and the ability of children to cooperate because of age or other factors. Conclusions More recent interesting approaches that seal enamel caries, only partially remove carious dentine or attempt to entirely seal carious dentine lesions merit not only discussion but also longer term investigation. With increasing demands on health funding, dentistry must look at how the most appropriate care can be provided to allow children to reach adulthood with healthy permanent dentitions - something that less than half the population currently achieve.

\section{EDITOR'S SUMMARY}

Information overload or indeed polythenia gravis, ${ }^{1}$ as the $B M J$ named it in a 'spoof' Christmas article many years ago, is something that most of us suffer these days. In the $B M J$ 's fictional case report about polythenia gravis a senior physician fractured the neck of his femur as a result of slipping on a pile of journals still in their plastic wrappers lying on the floor beside his bed. Another symptom was the increasing sense of guilt and inadequacy associated with his inability to keep up with the journals'. Joking aside, having too much information is a modern day issue facing all of us and we welcome anything that helps us keep up with relentless research and evidence.

This BDJ review article certainly helps to protect against the infliction of polythenia gravis. It presents a succinct review of current literature on the management of early childhood caries. It also usefully sums up recent research studies that show how dental care impacts on a child's health and wellbeing.
Less than half of children in the UK reach adulthood with healthy permanent dentitions. 'Baby teeth don't matter though do they? They are just practice teeth,' a friend of mine said to me just the other day.

But baby teeth do matter. This $B D J$ review shows that recent studies suggest that not only do primary teeth matter but they can be difficult to restore once diseased for various reasons discussed in the paper. Not only do they matter but they will have a significant impact on a child's quality of life. Not only do they matter but they could have a substantial effect on the possibility of a child having general health problems and major dental problems in the permanent dentition.

This paper acknowledges that children are a challenge to treat. They are often squirmy, tricky to understand and don't even let you or their carer know when they are in pain. Older children are frequently fed up of being told what to do and don't yet have the impetus to take responsibility for their own health. As well as describing the impact of problems in the primary dentition on wider oral and general health, the paper provides a review of recent research on why it's important to persevere with the management of early childhood caries. It also explores the outcomes of restorative care in the primary dentition and options for sealing in carious lesions rather than removing carious dentine. So stave off polythenia gravis and use this review to catch up on the reasons why it is worth providing restorative care to even the most awkward child.

The full paper can be accessed from the $B D J$ website (www.bdj.co.uk), under 'Research' in the table of contents for Volume 214 issue 11.

\section{Ruth Doherty} Managing Editor

1. Polythenia gravis: the downside of evidence based medicine. BMJ 1995; 311: 1666.

DOI: 10.1038/sj.bdj.2013.558 


\section{TO ACCESS THE BDJ WEBSITE TO READ THE FULL PAPER:}

- BDA Members should go to www.bda.org.

- Click the 'login' button on the right-hand side and enter your BDA login details.

- Once you have logged in click the 'BDJ' tab to transfer to the BDJ website with full access.

IF YOUR LOGIN DETAILS DO NOT WORK:

- Get a password reminder: go to www.bda.org, click the login button on the right-hand side and then click the forgotten password link.

- Use a recommended browser: we recommend Microsoft Internet Explorer or Mozilla Firefox.

- Ensure that the security settings on your browser are set to recommended levels.

IF YOU HAVE NOT YET SIGNED UP TO USE THE BDA WEBSITE:

- Go to www.bda.org/getstarted for information on how to start using the BDA website.
IN BRIEF

- Reviews evidence for the improvement of children's oral health-related quality of life with dental care.

- Considers the risks for poor oral health and general health in adolescents who had early childhood caries.

- Discusses approaches to controlling dental caries by sealing at different stages of lesion progression.

\section{COMMENTARY}

This paper by Drummond, Meldrum and Boyd brings further into focus the importance of children's oral health in relation to their quality of life and well being.

Save the Children reported in November 2012 that global inequalities in wealth are at their highest level for 20 years and are growing. Should you be lulled into a false sense of security as a resident of a developed country (UK) then be aware that some $20.2 \%$ of children nationally in the UK are living below the official poverty level. ${ }^{1}$ Not surprisingly there is a huge disparity in regions with almost $47 \%$ of children in the Manchester central parliamentary constituency living in households earning less than $60 \%$ of median income compared with $6 \%$ in Wimbledon. ${ }^{2}$ All children should have equal access to dental care.

There is evidence in Scotland through the National Dental Inspection Programmes that the percentage of fiveyear-olds with no decay has improved in 15 years from some 40 to $64 \%$. However, it would be wishful thinking to expect preventive programmes to be a 'cure all' because caries development is mostly a function of disordered and chaotic parenting where inappropriate foods and drinks are given at inappropriate times. In England and Wales some 32,000 children are the subjects of child protection plans at any one time and for $45 \%$ of these children it is because of neglect.

This paper is timely as it asks us to consider all available strategies to reduce progressive decay including the newer and novel treatment strategies and because the latter are generally easier, they may also help the previously pre-cooperative child to develop better coping skills. Additionally these newer novel strategies may be cheaper than conventional treatment. This will certainly help because we are already aware that funding for dentistry as a whole is being squeezed in the newer commissioning scenarios. Add to this is the fact that funding for the care of children's teeth is competing against the dental needs of an increasingly aged population. Children cannot advocate for themselves so we must as a caring profession advocate for them to achieve appropriate care.

\section{Richard Welbury}

Professor of Paediatric Dentistry

University of Glasgow Dental School

1. Inequality 'highest for 20 years'- Save the Children. BBC News, 1 November 2012. Online article available at $h t t p: / / w w w . b b c . c o . u k / n e w s /$ world-20156365 (accessed April 2013).

2. Campaign reveals 'wide disparity' in UK child poverty. BBC News, 20 February 2013. Online article available at $h t t p: / / w w w . b b c . c o . u k / n e w s /$ education-21511583 (accessed April 2013).

\section{AUTHOR QUESTIONS AND ANSWERS}

1. Why did you undertake this research? This review was undertaken to consider the evidence for the impact of dental restorative care on the oral health related quality of life of children.

2. What would you like to do next in this area to follow on from this work?

Dorothy Boyd already has a project investigating the impact of Hall crowns on the oral health related quality of life of children. Bernadette Drummond and others are investigating the oral health and general health in adolescents who were treated for early childhood caries. 